\title{
Pancreatitis aguda, ¿otra manifestación de COVID-19?
}

\section{Acute pancreatitis, another manifestation of COVID-19?}

\author{
Luis Ángel Rodríguez-Chávez' \\ https://orcid.org/0000-000I-7704-2530
}

Rodríguez-Chávez L, Vargas-Machuca Carranza C. Pancreatitis aguda, ¿otra manifestación de COVID-19?. Rev Soc Peru Med Interna. 2021;34(I): 9-1I.

https://doi.org/10.36393/spmi.v34i1.578

\section{Christian Alberto Vargas-Machuca Carranza² https://orcid.org/0000-0002-2756-9/55}

\begin{abstract}
RESUMEN
La COVID-19 tiene manifestaciones extrapulmonares variadas. Dada su capacidad de comprometer el sistema digestivo, se ha encontrado manifestaciones como dolor abdominal, diarrea, síndrome de mala absorción, etc. Se presenta el caso de un paciente que inició con sintomatología respiratoria de COVID-19 que, posteriormente, evolucionó a pancreatitis aguda necrotizante severa que finalmente le ocasionó la muerte. Se revisa la literatura al respecto.
\end{abstract}

Palabras clave: COVID-9, pancreatitis aguda.

\begin{abstract}
COVID-I 9 has varied extrapulmonary manifestations. Given its ability to compromise the digestive system, manifestations such as abdominal pain, diarrhea, poor absorption syndrome, etc. have been found. This is the case of a patient who started with respiratory symptomatology of COVID-19 who subsequently evolved into severe necrotizing acute pancreatitis that eventually his death. The literature is reviewed.
\end{abstract}

\section{Keywords: COVID-19, acute pancreatitis}

\section{INTRODUCCION}

La COVID-19 es conocida por ser una enfermedad respiratoria, de ahí que la principal complicación y causa de muerte es la neumonía, proceso inflamatorio que progresa a síndrome de dificultad respiratorio. Si bien la afirmación antes mencionada es cierta, la COVID-19 en realidad es

Médico internista del Hospital de Alta Complejidad Virgen de la Puerta-EsSalud, Trujillo. Universidad Privada Antenor Orrego, Trujillo, Perú.

2 Médico residente de medicina interna. Hospital de Alta Complejidad Virgen de la Puerta-EsSalud, Trujillo, Perú una enfermedad sistémica y se puede afectar cualquier órgano (preferentemente aquellos que expresan receptores ACE II, tales como riñón, corazón, tracto gastrointestinal); se ha reportado un amplio y complejo conjunto de sintomas y casos como pericarditis, miocarditis, insuficiencia renal, lesiones dérmicas tipo vasculitis y hasta encefalitis, etc. ${ }^{1,2}$ Reportamos un caso de pancreatitis aguda necrotizante severa en el contexto de COVID-19 y se revisa la literatura al respecto.

\section{PRESENTACIÓN DEL CASO}

Paciente varón de 54 años de edad, sin comorbilidades de base, con antecedente de laparotomía por peritonitis en el 2015. Inicia sintomatología respiratoria el 26 de junio del 2020 caracterizado por dolor de garganta, cefalea, malestar general y tos escasa intermitente lo que atribuyó a resfrío. Para el 4 de julio la tos se intensifica, así como el malestar general, por lo que acude a centro de salud donde realizan prueba rápida COVID-19 encontrándose IgM positivo e IgG negativo, por lo que paciente se automedicó dos días con ivermectina $(6 \mathrm{mg} / \mathrm{dl})$ una gota por kilo al día por dos días y azitromicina $500 \mathrm{mg}$ una tableta al día, por 5 días. E1 8 de julio acude nuevamente a centro de salud debido a 


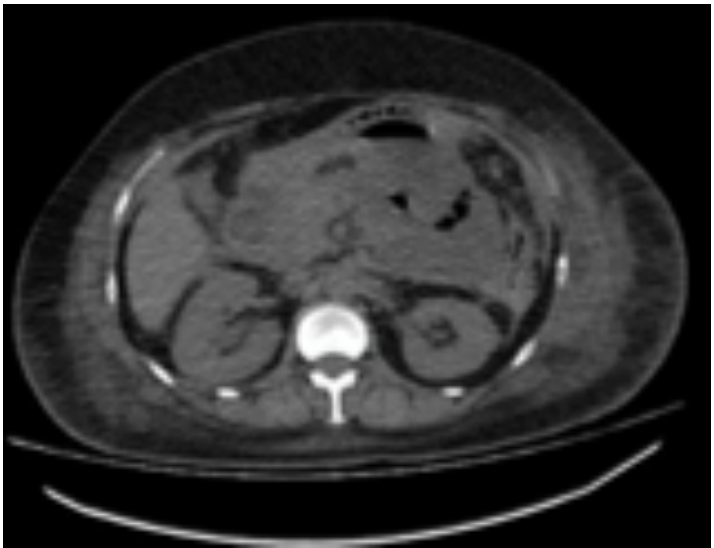

Figura I. Proceso de pancreatitis aguda.

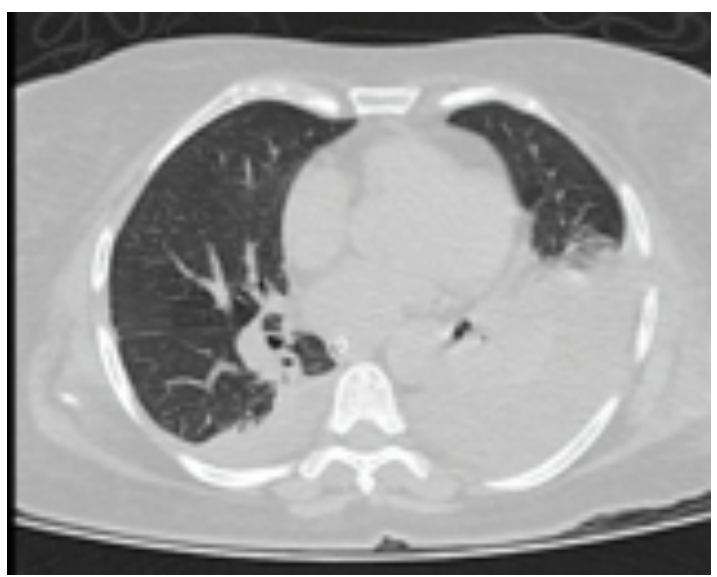

Figura 2. Derrame pleural a predominio izquierdo.

que tos seca se intensifica, persiste la fiebre y aparece dolor en la región posterior derecho del tórax, disnea asociada a tos exigente, signos vitales estables por lo que es enviado a domicilio y continúa en observación.

El 14 de julio inicia con dolor abdominal tipo cólico en epigastrio de intensidad moderada, asociado a náuseas y vómitos intermitentes de contenido alimentario que se intensifica al día siguiente por lo que acude a centro de salud donde reportan que al examen físico paciente presenta dolor a la palpación superficial en el epigastrio y es referido a hospital de mayor complejidad.

En el hospital, al paciente se le realizan los estudios correspondientes y la tomografía abdominal reporta pancreatitis aguda grave según índice de Mortele (necrosis pancreática, colección peripancreática y derrame pleural; cálculo en la vesícula biliar sin signos de colecistitis), evidenciándose pancreatitis aguda necrotizante severa, la evolución es tórpida, llegando incluso a ser intervenido quirúrgicamente. El reporte operatorio menciona: apertura de cavidad por línea media, disección roma y cortante, drenaje de colección, lavado y remoción de necrosis, liberación de asas intestinales, colocación de dren mixto en lecho de colección y dren laminar en el espacio parietocólico derecho. El paciente fallece 30 días después de su ingreso hospitalario.

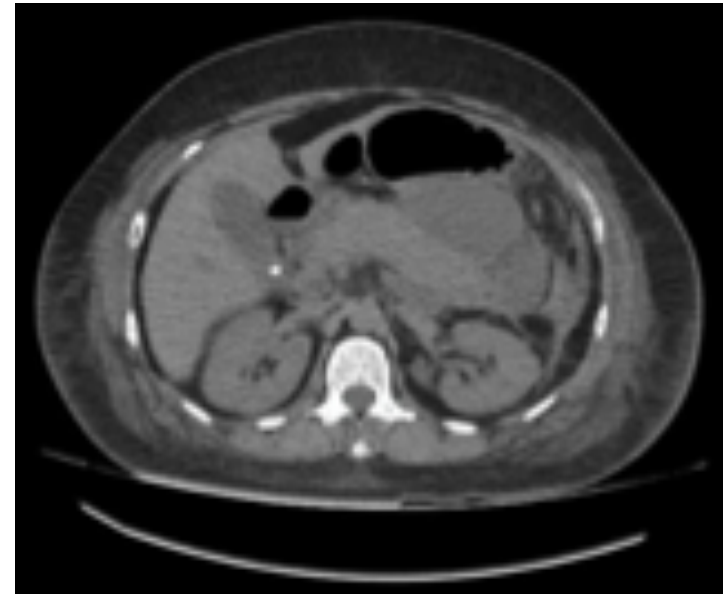

Figura 3. Litiasis vesicular.

\section{DISCUSIÓN}

La pancreatitis viral ha sido bien descrita en la literatura, más comúnmente por paperas, sarampión, coxsackie, virus de Epstein-Barr y virus de la hepatitis A. ${ }^{3}$ En la actualidad se ha reportado casos de pancreatitis aguda asociada a

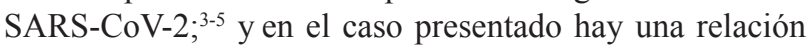
entre el inicio de los síntomas de COVID-19 y la posterior aparición del cuadro de pancreatitis aguda severa, curso clínico que coincide con otros casos de pancreatitis asociada a COVID-19.

Al respecto de la afectación pancreática por COVID-19, se menciona que podría deberse a dos mecanismos: un efecto directo del virus sobre el páncreas que, posteriormente, induce a la inflamación local ya que el páncreas también expresa los receptores ACE II o debido a que la sintomatología aparece posteriormente (en fase inflamatoria de la enfermedad) sería un proceso de respuesta inmunomediada. ${ }^{6,7} \mathrm{Al}$ parecer la pancreatitis aguda en COVID-19 es más frecuente de lo que se piensa. Así, Furong Liu ${ }^{7}$ en su estudio encontró que pacientes leves y graves con COVID-19 tenían pancreatitis leve y que entre el 1 a $2 \%$ de casos leves de COVID-19 cursa con pancreatitis; sin embargo, ésta es más frecuente en casos severos de COVID-19, tal es así que de 67 casos graves, 11 pacientes $(16,41 \%)$ mostraron niveles elevados tanto de amilasa como de lipasa, 5 pacientes $(7,46 \%)$ mostraron alteraciones en la imagen tomográfica y solo un paciente $(1,85 \%)$ mostró niveles elevados tanto de amilasa como de lipasa en 54 casos leves, sin cambios en la imagen.

Los casos reportados de pancreatitis asociado a COVID-19 cada vez son mayores, incluso se ha observado casos de pancreatitis aguda recurrente ${ }^{8} \mathrm{y}$ de afectación familiar ${ }^{9}$ asociado a COVID-19. Teniendo en cuenta que una de las manifestaciones gastrointestinales de la COVID-19 es dolor abdominal ${ }^{2}$ resultaría de importancia en ellos medir la lipasa o amilasa ya que podrían estar dentro del contexto de una pancreatitis aguda leve que suponemos quizás esté siendo infradiagnosticada y si este repercutiendo en la morbimortalidad de los pacientes, ya que el manejo de 
dichos casos podría ser diferente (asociar reposo pancreático asociado al tipo de nutrición, por ejemplo).

$\mathrm{Si}$ bien en nuestro caso, tal como en los otros casos reportados en la literatura, la pancreatitis aguda aparece dentro del contexto clínico de la COVID-19, encontramos que el paciente también presentaba litiasis de la vesícula biliar aunque sin signos de colecistitis, que podría también haber sido la causa de la pancreatitis aguda, pudiendo ser esta independiente de la COVID-19 o facilitada por el proceso inflamatorio de la misma.

\section{REFERENCIAS BIBLIOGRÁFICAS}

I. Gupta A, Madhavan MV, Sehgal K, Nair N, Mahajan S, Sehrawat TS, et al. Extrapulmonary manifestations of COVID-19. Nat Med. julio de 2020;26(7): 1017-32.

2. Behzad S, Aghaghazvini L, Radmard AR, Gholamrezanezhad A Extrapulmonary manifestations of COVID-19: Radiologic and clinical overview. Clin Imaging. I de octubre de 2020;66:35-4I.
3. Meireles PA, Bessa F, Gaspar P, Parreira I, Silva VD, Mota C, et al. Acalculous Acute Pancreatitis in a COVID- 19 Patient. Eur J Case Rep Intern Med [Internet]. I 3 de mayo de 2020 [citado I 8 de septiembre de 2020];7(6). URL disponible en: https://www.ncbi.nlm.nih.gov/ pmc/articles/PMC7279899/

4. Anand ER, Major C, Pickering O, Nelson M. Acute pancreatitis in a COVID-19 patient. Br J Surg. junio de 2020; I07(7):el 82.

5. Aloysius MM, Thatti A, Gupta A, Sharma N, Bansal P, Goyal H. COVID-19 presenting as acute pancreatitis. Pancreatology. julio de 2020;20(5): 1026-7.

6. Yang J-K, Lin S-S, Ji X-J, Guo L-M. Binding of SARS coronavirus to its receptor damages islets and causes acute diabetes. Acta Diabetol. 2010;47(3): 193-9.

7. Liu F, Long X, Zou W, Fang M, Wu W, Li W, et al. Highly ACE2 Expression in Pancreas May Cause Pancreas Damage After SARSCoV-2 Infection. medRxiv. 3 de marzo de 2020;2020.02.28.2002918I.

8. Cheung S, Fuentes AD, Fetterman AD. Recurrent Acute Pancreatitis in a Patient with COVID-I9 Infection. Am J Case Rep. 24 de agosto de 2020;2I:e927076-I-e927076-3.

9. Hadi A, Werge M, Kristiansen KT, Pedersen UG, Karstensen JG, Novovic S, et al. Coronavirus Disease-19 (COVID-19) associated with severe acute pancreatitis: Case report on three family members. Pancreatology. junio de 2020;20(4):665-7.

CORRESPONDENCIA:

Luis Ángel Rodríguez-Chávez

luisangelI982@htmail.com

Fecha de recepción: || |- ||-2020.

Fecha de aceptación: 10-01-2021. 